\title{
Antioxidant Activities and Phytochemical Study of Leaf Extracts from 18 Indigenous Tree Species in Taiwan
}

\author{
Shang-Tse Ho, ${ }^{1}$ Yu-Tang Tung, ${ }^{2}$ Yong-Long Chen, ${ }^{1}$ Ying-Ying Zhao, ${ }^{1}$ \\ Min-Jay Chung, ${ }^{3}$ and Jyh-Horng $\mathrm{Wu}^{1}$ \\ ${ }^{1}$ Department of Forestry, National Chung Hsing University, Taichung 402, Taiwan \\ ${ }^{2}$ Department of Life Sciences, National Chung Hsing University, Taichung 402, Taiwan \\ ${ }^{3}$ The Experimental Forest, National Taiwan University, Taipei 106, Taiwan
}

Correspondence should be addressed to Jyh-Horng Wu, eric@nchu.edu.tw

Received 30 June 2011; Accepted 25 October 2011

Academic Editor: Virginia S. Martino

Copyright (C) 2012 Shang-Tse Ho et al. This is an open access article distributed under the Creative Commons Attribution License, which permits unrestricted use, distribution, and reproduction in any medium, provided the original work is properly cited.

\begin{abstract}
The objective of this study is to assess antioxidant activities of methanolic extracts from the leaves of 18 indigenous tree species in Taiwan. Results revealed that, among 18 species, Acer oliverianum exhibited the best free radical scavenging activities. The $\mathrm{IC}_{50}$ values were 5.8 and $11.8 \mu \mathrm{g} / \mathrm{mL}$ on DPPH radical and superoxide radical scavenging activities, respectively. In addition, A. oliverianum also exhibited the strongest ferrous ion chelating activity. Based on a bioactivity-guided isolation principle, the resulting methanolic crude extracts of $A$. oliverianum leaves were fractionated to yield soluble fractions of hexane, EtOAc, $\mathrm{BuOH}$, and water. Of these, the EtOAc fraction had the best antioxidant activity. Furthermore, 8 specific phytochemicals were isolated and identified from the EtOAc fraction. Among them, 1,2,3,4,6-O-penta-galloyl- $\beta$-D-glucopyranose had the best free radical scavenging activity. These results demonstrate that methanolic extracts and their derived phytochemicals of $A$. oliverianum leaves have excellent antioxidant activities and thus they have great potential as sources for natural health products.
\end{abstract}

\section{Introduction}

Molecular and cellular damage due to reactive oxygen species (ROS) is widely believed to be the major cause of aging, neural disorders, diabetes, atherosclerosis, inflammatory injury, cancer, and cardiovascular disease [1]. Thus, a potential scavenger of ROS may serve as a possible preventive intervention for free-radical-mediated diseases [2]. Plants are potential sources of natural antioxidants. In the past few years, the antioxidant properties of plants have been extensively studied $[3,4]$. Among the various medicinal and culinary plants, some endemic species are of particular interest because they may be used for preparations containing phytochemicals with significant antioxidant activities and health benefits [5]. Therefore, the intake of natural antioxidants from plants has been associated with low incidence of cancer, cardiovascular disease, diabetes, and other diseases associated with aging [6].

Taiwan is on the boundary of the tropics and subtropics, and although the island covers only a small area, the environment of Taiwan is diversified, possessing unique indigenous tree species in this island. However, to the best of our knowledge there is no prior report on antioxidative phytochemicals of leaf extracts of indigenous tree species in Taiwan. Thus, in this study, a number of in vitro assays were performed to evaluate the antioxidant activities of methanolic extracts from the leaves of 18 indigenous tree species. In addition, the characteristics of bioactive phytochemicals were also addressed in this study.

\section{Materials and Methods}

2.1. Extraction and Fractionation of 18 Indigenous Tree Species. The leaves of 18 indigenous tree species in Taiwan were collected at the end of May 2009 from the Hui-Sun Forest Station of National Chung Hsing University (NCHU) in Nantou County. All voucher specimens including Acacia confusa Merr. (Lu 0069), Acer oliverianum Pax. var. nakaharai (Peng 0001), Calocedrus formosana Florin (Tsai et al. S.N.), 
Cunninghamia lanceolata Hook. var. konishii (Lin 0002), Cunninghamia lanceolata Hook. var. lanceolata (Hsu 0013), Cryptomeria japonica D. Don (Wang 0007), Evodia lepta Merr. (Wu 0030), Fraxinus formosana Hay. (Tseng 2706), Helicia rengetiensis Masamune (Tseng 2588), Liquidambar formosana Hance (Liu 0007), Machilus kusanoi Hay. (Chen 0025), Neolitsea konishii Kaneh. et Sasaki (Ou et al. 7355), Pinus morrisonicola Hay. (Chiu 4127), Pinus taiwanensis Hay. (Ou et al. 9007), Styrax formosana Matsum. (Lin 0018), Taiwania cryptomerioides Hay. (Liu S.N.), Viburnum luzonicum Rolfe (Chen 0049), and Zelkova serrata Makino (Lu et Ou 0964) were deposited at the herbarium of the Department of Forestry, NCHU. The species were identified by Dr. YenHsueh Tseng (Department of Forestry, NCHU). The samples were cleaned with tap water and dried. Then they were extracted with methanol by ultrasound-assisted extraction for $30 \mathrm{~min}$ at room temperature two times. The leaf extracts of 18 indigenous tree species were decanted, filtered under vacuum, concentrated in a rotary evaporator, and then lyophilized. Furthermore, the resulting methanolic crude extracts of A. oliverianum were fractionated successively with $n$-hexane, ethyl acetate (EtOAc), $n$-butanol $(\mathrm{BuOH})$, and water to yield soluble fractions of hexane, EtOAc, $\mathrm{BuOH}$, and water. All extracts were stored in an airtight container at $-40^{\circ} \mathrm{C}$ prior to further analysis.

2.2. 1,1-Diphenyl-2-picrylhydrazyl Assay (DPPH Assay). The $\mathrm{DPPH}$ radical scavenging activity of the test extracts was examined according to the method reported by Tung et al. [7]. Ten microliters of the test samples in methanol was mixed with $200 \mu \mathrm{L}$ of $0.1 \mathrm{mM}$ DPPH-ethanol solution and $90 \mu \mathrm{L}$ of $50 \mathrm{mM}$ Tris-HCl buffer ( $\mathrm{pH} 7.4)$. Methanol (10 $\mu \mathrm{L})$ alone was used as the control of this experiment. After $30 \mathrm{~min}$ of incubation at room temperature, the reduction in DPPH radicals was measured by reading the absorbance at $517 \mathrm{~nm}$. $(+)$-Catechin was used as the positive control. The inhibition ratio was calculated using the following equation:

$$
\begin{aligned}
& \% \text { inhibition } \\
& =\frac{\text { absorbance of control }- \text { absorbance of test sample }}{\text { absorbance of control }} \\
& \quad \times 100 \text {. }
\end{aligned}
$$

2.3. Superoxide Radical Scavenging Assay (NBT Assay). Measurement of superoxide radical scavenging activity was carried out according to the method of Ho et al. [8]. First, $20 \mu \mathrm{L}$ of $15 \mathrm{mM} \mathrm{Na}_{2}$ EDTA in buffer (50 mM KH $\mathrm{PO}_{4} / \mathrm{KOH}, \mathrm{pH}$ 7.4), $50 \mu \mathrm{L}$ of $0.6 \mathrm{mM}$ NBT in buffer, $30 \mu \mathrm{L}$ of $3 \mathrm{mM}$ hypoxanthine in $50 \mathrm{mM} \mathrm{KOH}, 5 \mu \mathrm{L}$ of test samples in methanol, and $145 \mu \mathrm{L}$ of buffer were mixed in 96-well microplates. The reaction was started by adding $50 \mu \mathrm{L}$ of xanthine oxidase solution in buffer ( 1 unit in $10 \mathrm{~mL}$ buffer) to the mixture. The reaction mixture was incubated at room temperature, and the absorbance at $570 \mathrm{~nm}$ was determined every 1 min up to 9 min using a plate reader (Labsystems Multiskan MS, Finland). The control was
$5 \mu \mathrm{L}$ of methanol instead of the sample solution. (+)-Catechin was used as the positive control. The inhibition ratio was calculated using the following equation:

$$
\begin{aligned}
\% & \text { Inhibition } \\
= & \frac{\text { rate of control reaction }- \text { rate of sample reaction }}{\text { rate of control reaction }} \\
& \times 100 .
\end{aligned}
$$

2.4. Ferrous Ion Chelating Assay. The ferrous ion chelating potential of the test samples was evaluated according to the method of Tung et al. [9]. Briefly, $200 \mu \mathrm{L}$ of the test samples in methanol and $740 \mu \mathrm{L}$ methanol were added to $20 \mu \mathrm{L}$ of $2 \mathrm{mM} \mathrm{FeCl}_{2}$. The reaction was initiated by adding $40 \mu \mathrm{L}$ of $5 \mathrm{mM}$ ferrozine. The mixture was shaken vigorously and rested at room temperature for $10 \mathrm{~min}$. Absorbance of the solution was then measured at $562 \mathrm{~nm}$. EDTA was used as a positive control. The percent of inhibition of $\mathrm{Fe}^{2+}$-ferrozine complex formation was calculated according to the following equation:

$$
\begin{aligned}
& \% \text { inhibition } \\
& =\frac{\text { absorbance of control }- \text { absorbance of sample }}{\text { absorbance of control }} \\
& \quad \times 100 .
\end{aligned}
$$

2.5. Determination of Total Phenolics of Different Indigenous Species in Taiwan. Total phenolic contents were determined according to the Folin-Ciocalteu method [10], using gallic acid as the standard. The test samples $(5 \mathrm{mg})$ were dissolved in $5 \mathrm{~mL}$ of methanol/water $(50: 50, \mathrm{v} / \mathrm{v})$. The extract solution $(500 \mu \mathrm{L})$ was mixed with $500 \mu \mathrm{L}$ of $50 \%$ Folin-Ciocalteu reagent. The mixture was kept for $5 \mathrm{~min}$, which was followed by the addition of $1.0 \mathrm{~mL}$ of $20 \% \mathrm{Na}_{2} \mathrm{CO}_{3}$. After $10 \mathrm{~min}$ of incubation at room temperature, the mixture was centrifuged for $8 \mathrm{~min}(12000 \mathrm{~g})$, and the absorbance of the supernatant was measured at $730 \mathrm{~nm}$. The total phenolic content was expressed as gallic acid equivalents (GAE) in milligrams per gram sample.

2.6. Isolation and Identification of Bioactive Phytocompounds. Based on bioactivity-guide isolation principle, the EtOAc soluble fraction from the A. oliverianum had an excellent antioxidant activity, thus it was loaded into a chromatography column (Geduran Si-60, Merck, Darmstadt, Germany) and eluted with gradient $\mathrm{EtOAc/n}$-hexane and $\mathrm{MeOH} / \mathrm{EtOAc}$ solvent systems, and 9 subfractions (EA1-9) were obtained. The antioxidative phytochemicals from the EA5, EA6, and EA7 were separated and purified by semipreparative HPLC using a PU-2080 pump (Jasco, Japan) equipped with a MD2010 multiwavelength detector (Jasco, Japan) and a $250 \times$ $10.0 \mathrm{~mm}$ i.d., 5- $\mu \mathrm{m}$ Ascentis RP-amide column (Supelco, Bellefonte, USA). The mobile phase was solvent $A, 100 \%$ $\mathrm{MeOH}$; and solvent $B$, ultrapure water. Elution condition was $0-24 \mathrm{~min}$ of $4-100 \% A$ to $B$ (linear gradient) at a flow rate of $4 \mathrm{~mL} / \mathrm{min}$ for isolation of EA5. On the other hand, 
the elution condition was $0-5$ min of $40-64 \% A$ to $B$ (linear gradient), $5-11 \mathrm{~min}$ of $64 \% A$ to $B, 11-37 \mathrm{~min}$ of $64-85 \% A$ to $B$ (linear gradient), and $37-42 \mathrm{~min}$ of $85-100 \% A$ to $B$ (linear gradient) at a flow rate of $4 \mathrm{~mL} / \mathrm{min}$ for isolation of EA6 and EA7. The structures of compounds 1-8 were determined by MS (Finnigan MAT-95S, Germany) and ${ }^{1} \mathrm{H}$ NMR (Varian Unity Inova-600, USA), and all spectral data were consistent with the published literature [11-17].

2.7. Statistical Analysis. The significance of difference was calculated by Scheffe's test, and results with $P<0.05$ were considered statistically significant. Comparisons of total phenolic contents and various antioxidant activities were carried out using Pearson's correlation test.

\section{Results and Discussion}

3.1. The Yields of Methanolic Extracts of 18 Indigenous Tree Species in Taiwan. The leaves of 18 indigenous tree species in Taiwan yielded from 6.6 to $27.3 \%$ (w/w) methanolic extracts based on dry weight. Of these, the yields of 10 species, including S. formosana (27.3\%), V. luzonicum (21.4\%), F. formosana (16.7\%), E. lepta (16.1\%), L. formosana (15.7\%), P. morrisonicola (15.0\%), C. lanceolata var. konishii (12.5\%), $H$. rengetiensis (12.3\%), A. oliverianum (10.5\%), and A. confusa $(10.5 \%)$, were higher than $10 \%$. In addition, the yields among different species are very different, for example, the yield of S. formosana (27.3\%) is fourfold the N. konishii $(6.6 \%)$.

3.2. Antioxidant Activities of Methanolic Extracts of 18 Indigenous Tree Species in Taiwan. As for the inhibitory effects of the leaf extracts from 18 indigenous species in Taiwan on DPPH radicals, data in Table 1 shows that most extracts revealed a good scavenging activity for $\mathrm{DPPH}$ radicals. The $\mathrm{IC}_{50}$ values (the concentration required to inhibit radical formation by $50 \%$ ) of crude extracts increased in the following order: A. oliverianum $(5.8 \mu \mathrm{g} / \mathrm{mL})>Z$. serrata $(9.7 \mu \mathrm{g} / \mathrm{mL})>$ A. confusa $(12.9 \mu \mathrm{g} / \mathrm{mL})>L$. formosana $(14.9 \mu \mathrm{g} / \mathrm{mL})>V$. luzonicum $(15.3 \mu \mathrm{g} / \mathrm{mL})>F$. formosana $(24.2 \mu \mathrm{g} / \mathrm{mL})>N$. konishii $(25.1 \mu \mathrm{g} / \mathrm{mL})>$ P. morrisonicola $(25.9 \mu \mathrm{g} / \mathrm{mL})>H$. rengetiensis $(31.6 \mu \mathrm{g} / \mathrm{mL})>C$. formosana $(33.3 \mu \mathrm{g} / \mathrm{mL})>T$. cryptomerioides $(35.9 \mu \mathrm{g} / \mathrm{mL})>C$. lanceolata var. konishii $(37.7 \mu \mathrm{g} / \mathrm{mL})>S$. formosana $(38.1 \mu \mathrm{g} / \mathrm{mL})>P$. taiwanensis $(38.3 \mu \mathrm{g} / \mathrm{mL})>$ M. kusanoi $(42.2 \mu \mathrm{g} / \mathrm{mL})>$ E. lepta $(76.7 \mu \mathrm{g} / \mathrm{mL})>$ C. japonica $(98.3 \mu \mathrm{g} / \mathrm{mL})>$ C. lanceolata var. lanceolata $(98.9 \mu \mathrm{g} / \mathrm{mL})$. Of these, the $\mathrm{IC}_{50}$ values of four species, including $A$. oliverianum, $Z$. serrata, $A$. confusa, and $L$. formosana, were lower than $15 \mu \mathrm{g} / \mathrm{mL}$. In comparison with a well-known antioxidant, $(+)$-catechin $\left(\mathrm{IC}_{50}=2.6 \mu \mathrm{g} / \mathrm{mL}\right)$, the crude extracts of the trees mentioned above exhibited a good DPPH radical-scavenging activity. Additionally, the crude extract of green tea showed an excellent inhibitory activity against DPPH radicals with $\mathrm{IC}_{50}$ value of $5 \mu \mathrm{g} / \mathrm{mL}$ [18]. Comparison of the results indicates that the leaf extracts of A. oliverianum would be an excellent source of natural antioxidants and merit further investigation.
Furthermore, superoxide radical scavenging activity of the test samples from different indigenous species in Taiwan was determined by the hypoxanthine-xanthine oxidase system. Table 1 shows the superoxide radical scavenging activity of various methanolic extracts compared with (+)-catechin. The inhibitory activity of 18 species was observed in a dosedependant manner, and the leaf extracts of A. oliverianum exhibited the highest superoxide radical scavenging activity among all species. The $\mathrm{IC}_{50}$ values of $(+)$-catechin, $A$. confusa, A. oliverianum, C. formosana, C. japonica, C. lanceolata var. lanceolata, C. lanceolata var. konishii, E. lepta, F. formosana, $H$. rengetiensis, L. formosana, M. kusanoi, N. konishii, P. morrisonicola, P. taiwanensis, S. formosana, T. cryptomerioides, $V$. luzonicum, and $Z$. serrata were $8.8,22.3,11.8,35.8$, $>100,>100,44.2$, >100, 44.4, 42.6, 30.9, >100, 37.3, 26.1, $38.7,21.9,36.0,24.7$, and $23.6 \mu \mathrm{g} / \mathrm{mL}$, respectively. This result was similar to that of DPPH assay for all the species, $A$. oliverianum exhibited the strongest superoxide radical scavenging activity.

On the other hand, the chelating effect of the test sample on ferrous ions is also shown in Table 1. Results revealed that $\mathrm{IC}_{50}$ values of chelating effect for various leaf extracts were as follows: A. oliverianum $(88.1 \mu \mathrm{g} / \mathrm{mL})>$ L. formosana $(123.1 \mu \mathrm{g} / \mathrm{mL})>$ M. kusanoi $(185.3 \mu \mathrm{g} / \mathrm{mL})>N$. konishii $(251.6 \mu \mathrm{g} / \mathrm{mL})>$ C. lanceolata var. lanceolata $(297.9 \mu \mathrm{g} / \mathrm{mL})>$ V. luzonicum $(316.3 \mu \mathrm{g} / \mathrm{mL})>$ A. confusa $(356.7 \mu \mathrm{g} / \mathrm{mL})>Z$. serrata $(397.0 \mu \mathrm{g} / \mathrm{mL})>$ C. lanceolata var. konishii $(439.5 \mu \mathrm{g} /$ $\mathrm{mL})>$ E. lepta $(581.1 \mu \mathrm{g} / \mathrm{mL})>$ C. formosana $(607.9 \mu \mathrm{g} / \mathrm{mL})>$ F. formosana $(654.5 \mu \mathrm{g} / \mathrm{mL})>T$. cryptomerioides $(795.3 \mu \mathrm{g} /$ $\mathrm{mL})>$ P. morrisonicola $(885.3 \mu \mathrm{g} / \mathrm{mL})>$ S. formosana $(907.5 \mu \mathrm{g} / \mathrm{mL})>$ C. japonica $(>1000 \mu \mathrm{g} / \mathrm{mL})=H$. rengetiensis $(>1000 \mu \mathrm{g} / \mathrm{mL})=$ P. taiwanensis $(>1000 \mu \mathrm{g} / \mathrm{mL})$. Comparison of the aforementioned results obtained from free radical scavenging activities indicated that the ferrous ion chelating effect of methanolic extracts did not correlate with the results from DPPH and NBT assays used to estimate antioxidant activities. This discrepancy in the antioxidant assays may be due to different mechanisms involved in antioxidant assays. Furthermore, our findings are also in agreement with the results reported by Chua et al. [19] and Tung et al. [20]. However, among 18 species, the leaf extracts of A. oliverianum still exhibited better ferrous ion chelating effect than others.

3.3. Total Phenolics of Methanolic Extracts of 18 Indigenous Tree Species in Taiwan. It is well known that plant phenolics (e.g., flavonoids and proanthocyanidins) are generally highly effective free radical scavengers and antioxidants. From the estimation of phenolic contents it can be observed that the polyphenolics and antioxidant activities are a combined measure of the quality and quantity of antioxidants. Table 1 shows that the contents of total phenolics in crude extracts were determined spectrometrically according to the FolinCiocateu method and calculated as gallic acid equivalents (GAE). Accordingly, total phenolic contents of different indigenous species in Taiwan were in decreasing order: A. oliverianum (311.7 mg GAE/g) > V. luzonicum (210.9 mg GAE/ g) $>$ Z. serrata $(200.9 \mathrm{mg} \mathrm{GAE} / \mathrm{g})>$ A. confusa $(190.2 \mathrm{mg}$ $\mathrm{GAE} / \mathrm{g})>$ F. formosana (183.9 mg GAE/g) > S. formosana 
TABLE 1: Antioxidant activities of methanolic extracts from the leaves of 18 indigenous tree species.

\begin{tabular}{|c|c|c|c|c|}
\hline \multirow{2}{*}{ Specimens } & \multicolumn{3}{|c|}{$\mathrm{IC}_{50}(\mu \mathrm{g} / \mathrm{mL})$} & \multirow{2}{*}{ Total phenolic content (mg GAE/g) } \\
\hline & DPPH radical & Superoxide radical & Ferrous-ion chelating & \\
\hline \multicolumn{5}{|l|}{ Softwood } \\
\hline C. formosana & $33.3 \pm 0.2^{\mathrm{DE}}$ & $35.8 \pm 0.8^{\mathrm{CD}}$ & $607.9 \pm 8.9^{\mathrm{C}}$ & $150.3 \pm 1.3^{\mathrm{E}}$ \\
\hline C. japonica & $98.3 \pm 2.3^{\mathrm{A}}$ & $>100$ & $>1000$ & $18.9 \pm 0.9^{J}$ \\
\hline C. lanceolata var. lanceolata & $98.9 \pm 2.4^{\mathrm{A}}$ & $>100$ & $297.9 \pm 3.1^{\mathrm{FG}}$ & $61.6 \pm 0.4^{\mathrm{HI}}$ \\
\hline C. lanceolata var. konishii & $37.7 \pm 0.6^{\mathrm{CD}}$ & $44.2 \pm 3.8^{\mathrm{A}}$ & $439.5 \pm 7.9^{\mathrm{D}}$ & $105.2 \pm 1.0^{\mathrm{FG}}$ \\
\hline P. morrisonicola & $25.9 \pm 0.2^{\mathrm{F}}$ & $26.1 \pm 0.7^{\mathrm{EF}}$ & $885.3 \pm 10.7^{\mathrm{A}}$ & $108.9 \pm 5.3^{\mathrm{FG}}$ \\
\hline P. taiwanensis & $38.3 \pm 1.6^{\mathrm{CD}}$ & $38.7 \pm 0.9^{\mathrm{ABC}}$ & $>1000$ & $120.1 \pm 1.0^{\mathrm{F}}$ \\
\hline T. cryptomerioides & $35.9 \pm 0.5^{\mathrm{DE}}$ & $36.0 \pm 1.4^{\mathrm{BCD}}$ & $795.3 \pm 11.3^{\mathrm{B}}$ & $70.1 \pm 1.5^{\mathrm{HI}}$ \\
\hline \multicolumn{5}{|l|}{ Hardwood } \\
\hline A. confusa & $12.9 \pm 0.0^{\mathrm{GH}}$ & $22.3 \pm 1.9^{\mathrm{F}}$ & $356.7 \pm 6.3^{\mathrm{DEF}}$ & $190.2 \pm 4.2^{\mathrm{CD}}$ \\
\hline A. oliverianum & $5.8 \pm 0.1^{\mathrm{IJ}}$ & $11.8 \pm 0.6^{\mathrm{G}}$ & $88.1 \pm 1.2^{\mathrm{JK}}$ & $311.7 \pm 7.7^{\mathrm{A}}$ \\
\hline E. lepta & $76.7 \pm 2.4^{\mathrm{B}}$ & $>100$ & $581.1 \pm 15.2^{\mathrm{C}}$ & $72.8 \pm 0.7^{\mathrm{H}}$ \\
\hline F. formosana & $24.2 \pm 0.4^{\mathrm{F}}$ & $44.4 \pm 1.7^{\mathrm{A}}$ & $654.5 \pm 8.7^{C}$ & $183.9 \pm 1.0^{\mathrm{D}}$ \\
\hline H. rengetiensis & $31.6 \pm 0.5^{\mathrm{E}}$ & $42.6 \pm 0.8^{\mathrm{AB}}$ & $>1000$ & $63.4 \pm 1.0^{\mathrm{HI}}$ \\
\hline L. formosana & $14.9 \pm 0.2^{\mathrm{G}}$ & $30.9 \pm 1.2^{\mathrm{DE}}$ & $123.1 \pm 2.0^{\mathrm{IJ}}$ & $147.4 \pm 4.8^{\mathrm{E}}$ \\
\hline M. kusanoi & $42.2 \pm 0.7^{\mathrm{C}}$ & $>100$ & $185.3 \pm 4.1^{\mathrm{HI}}$ & $54.7 \pm 0.3^{\mathrm{I}}$ \\
\hline N. konishii & $25.1 \pm 0.1^{\mathrm{F}}$ & $37.3 \pm 2.5^{\mathrm{BCD}}$ & $251.6 \pm 5.1^{\mathrm{GH}}$ & $100.0 \pm 2.0^{\mathrm{G}}$ \\
\hline S. formosana & $38.1 \pm 0.8^{\mathrm{CD}}$ & $21.9 \pm 0.8^{\mathrm{F}}$ & $907.5 \pm 69.3^{\mathrm{A}}$ & $151.5 \pm 3.4^{\mathrm{E}}$ \\
\hline V.luzonicum & $15.3 \pm 0.2^{\mathrm{G}}$ & $24.7 \pm 0.4^{\mathrm{EF}}$ & $316.3 \pm 1.9^{\mathrm{EFG}}$ & $210.9 \pm 5.1^{\mathrm{B}}$ \\
\hline Z. serrata & $9.7 \pm 0.2^{\mathrm{HI}}$ & $23.6 \pm 0.5^{\mathrm{F}}$ & $397.0 \pm 5.0^{\mathrm{DE}}$ & $200.9 \pm 3.4^{\mathrm{BC}}$ \\
\hline$(+)$-Catechin & $2.6 \pm 0.0^{J}$ & $8.8 \pm 0.3^{\mathrm{G}}$ & - & \\
\hline EDTA & - & - & $7.0 \pm 0.4^{\mathrm{K}}$ & \\
\hline
\end{tabular}

Results are mean $\pm \mathrm{SD}(n=3)$. Different capital letters in superscript indicate significant differences among groups $(P<0.05)$.

(151.5 mg GAE/g) > C. formosana $(150.3 \mathrm{mg} \mathrm{GAE} / \mathrm{g})>L$. formosana (147.4 mg GAE/g) > P. taiwanensis (120.1 mg $\mathrm{GAE} / \mathrm{g})>$ P. morrisonicola $(108.9 \mathrm{mg} \mathrm{GAE} / \mathrm{g})>$ C. lanceolata var. konishii (105.2 mg GAE/g) > N. konishii (100.0 mg GAE/g) > E. lepta (72.8 mg GAE/g) > T. cryptomerioides (70.1 mg GAE/g) > H. rengetiensis $(63.4 \mathrm{mg} \mathrm{GAE} / \mathrm{g})>C$. lanceolata var. lanceolata $(61.6 \mathrm{mg} \mathrm{GAE} / \mathrm{g})>$ M. kusanoi (54.7 mg GAE/g) > C. japonica (18.9 mg GAE/g). This result revealed that $A$. oliverianum, $V$. luzonicum, $Z$. serrata, and $A$. confusa leaf extracts showed the higher phenolic contents, which correlated with the results of free radical scavenging activities. Previous report also found that the antioxidant effects of phenolics are strongly dependent on the choice of raw materials because the antioxidant activities differ between different phenolic constituents [21]. On the basis of the results obtained, effective antioxidants from methanolic extracts of $A$. oliverianum leaves can be obtained to separate and purify.

3.4. Correlation Coefficients among DPPH Radical Scavenging Activity, Superoxide Radical Scavenging Activity, Ferrous Ion Chelating Ability, and Total Phenolic Contents in Extracts. Phenolic compounds are very important plant constituents because of their scavenging ability due to their hydroxyl groups. Thus, the correlation between the total phenolic contents and antioxidant activities has been widely studied in different plants or foodstuffs [22-25]. In this study, correlation coefficients for total phenolic contents with the DPPH,
TABle 2: Correlation coefficients among DPPH radical scavenging activity (DPPH assay), superoxide radical scavenging activity (NBT assay), ferrous ion chelating ability (Chelating assay), and total phenolic contents (TPC) in extracts.

\begin{tabular}{lcccc}
\hline & DPPH assay & NBT assay & Chelating assay & TPC \\
\hline DPPH assay & - & $0.88^{* *}$ & 0.37 & $0.71^{* *}$ \\
NBT assay & $0.88^{* *}$ & - & 0.15 & $0.72^{* *}$ \\
Chelating assay & 0.37 & 0.15 & - & $0.54^{*}$ \\
TPC & $0.71^{* *}$ & $0.72^{* *}$ & $0.54^{*}$ & - \\
\hline
\end{tabular}

${ }^{*} P<0.05 .{ }^{* *} P<0.01$.

NBT, and ferrous ion chelating assays are shown in Table 2. A linear relationship was also established between total phenolic content and antioxidant activities and it was observed that antioxidant activities increased proportionally to the phenolic contents. These results showed that strong correlations were obtained between total phenolic contents and DPPH assay, NBT assay, and ferrous ion chelating assay, with $R^{2}$ values of $0.71(P<0.01), 0.72(P<0.01)$, and $0.54(P<$ $0.05)$, respectively. Furthermore, antioxidant activities of extracts are correlated to their phenolic contents, and it is proposed that phenolic compounds from the methanolic extracts of $A$. oliverianum leaves may play an important role in antioxidant activities. Thus, the therapeutic properties of A. oliverianum may be attributed to the phenolic compounds. 


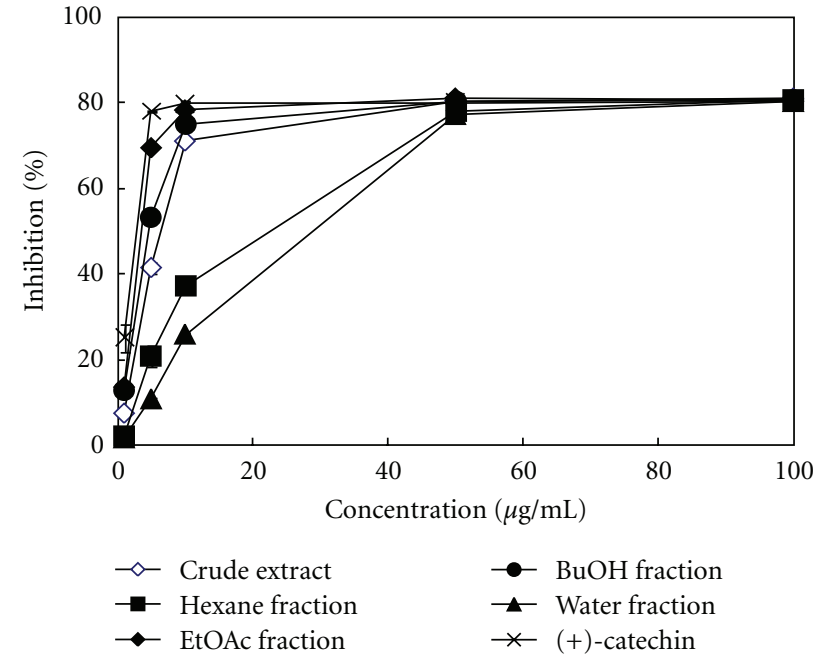

(a)

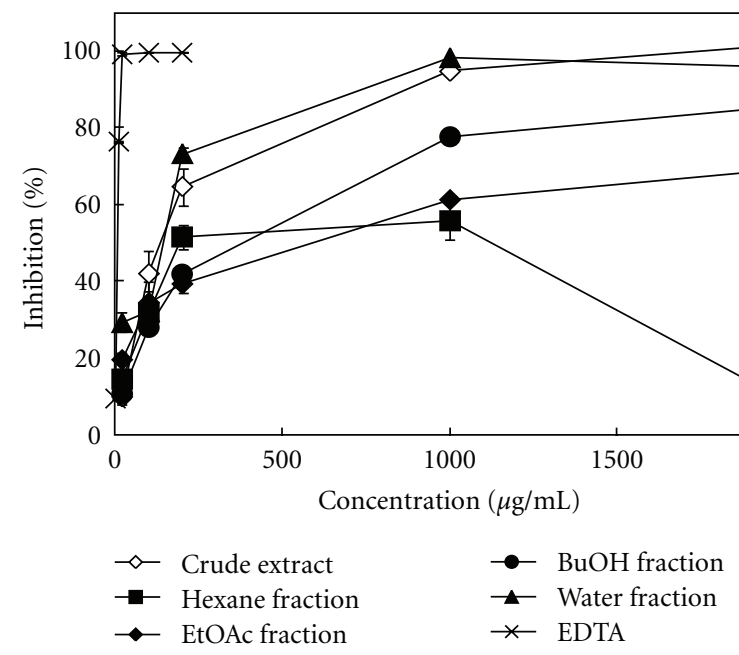

(c)
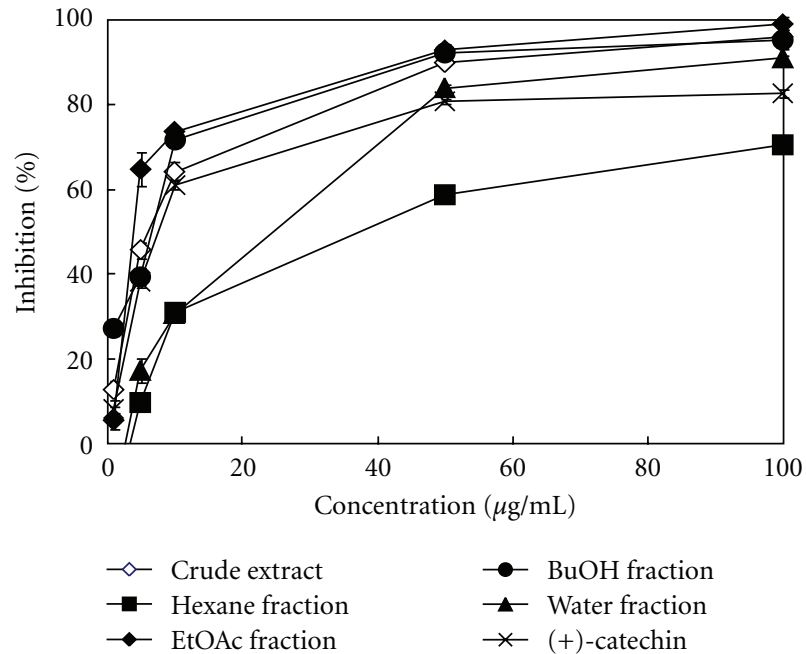

(b)

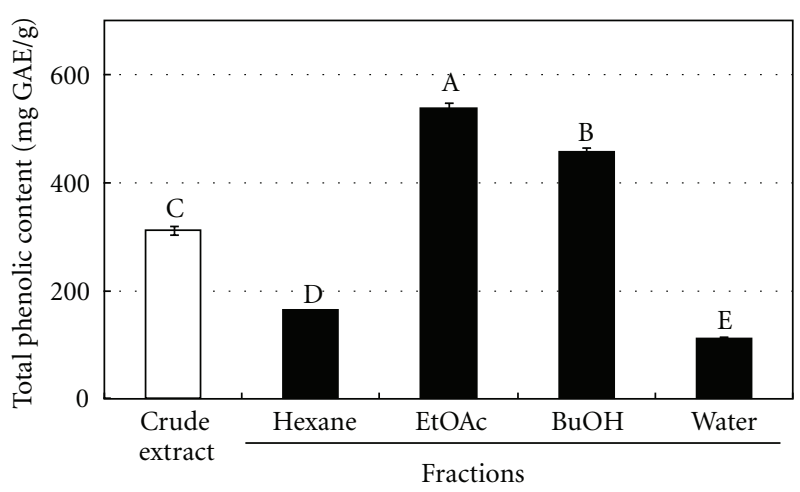

(d)

FIGURE 1: Antioxidant activities of methanolic extracts and their derived soluble fractions from the leaves of A. oliverianum. (a) DPPH radical scavenging activity. (b) Superoxide radical scavenging activity. (c) Ferrous ion chelating ability. (d) Total phenolic contents. Results are mean $\pm \mathrm{SD}(n=3)$. The bars marked by different letters are significantly different at the level of $P<0.05$ according to the Scheffe's test.

3.5. Isolation and Identification of Bioactive Phytocompounds. Based on bioactivity-guided isolation principle, the resulting methanolic crude extracts of $A$. oliverianum leaves were fractionated successively with $n$-hexane, ethyl acetate (EtOAc), $n$-butanol $(\mathrm{BuOH})$, and water to yield soluble fractions of hexane, EtOAc, BuOH, and water. As shown in Figure 1, the $\mathrm{DPPH}$ radical and superoxide radical scavenging activities of methanolic extracts and their derived soluble fractions from $A$. oliverianum leaves increased with increasing the concentration of the test sample. The $\mathrm{IC}_{50}$ values of crude extract, hexane fraction, EtOAc fraction, $\mathrm{BuOH}$ fraction, and water fraction of $A$. oliverianum leaves were 5.8, 16.3, 3.2, 4.1, and $20.3 \mu \mathrm{g} / \mathrm{mL}$ on DPPH assay (Figure $1(\mathrm{a})$ ); 11.8, 30.4, 3.9, 6.1, and $25.9 \mu \mathrm{g} / \mathrm{mL}$ on NBT assay (Figure 1(b)); 88.1, 191.3, $609.6,281.2$ and $150.3 \mu \mathrm{g} / \mathrm{mL}$ on ferrous ion chelating ability (Figure 1(c)), respectively. In addition, the total phenolic contents of crude extract, hexane fraction, EtOAc fraction,
$\mathrm{BuOH}$ fraction, and water fraction of $A$. oliverianum leaves were 311.7, 164.1, 537.2, 457.2, and 112.3 mg GAE/g (Figure $1(\mathrm{~d}))$. Accordingly, except for the ferrous ion chelating effect, the antioxidant activities of $A$. oliverianum leaves can be effectively enriched in the EtOAc fraction. It is well known that chelating agents are effective as secondary antioxidants because they reduce the redox potential, thereby stabilizing the oxidized form of the metal ion [26]. Therefore, the EtOAc soluble fraction from $A$. oliverianum leaves was not a good secondary antioxidant due to its poor capacity for metal ion binding, but it was an excellent primary antioxidant (or free radical scavenger). These results revealed that the EtOAc soluble fraction from the A. oliverianum leaves had a powerful antioxidant activity and it might be a good candidate to be developed as a novel natural antioxidant. Thus, the EtOAc soluble fraction was further derived into 9 subfractions by column chromatography. Table 3 shows the elution solvent, 


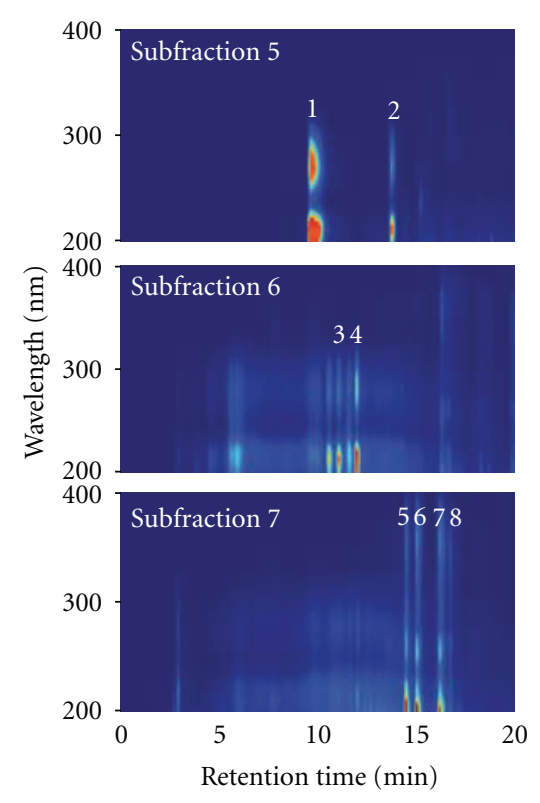<smiles>[R]OC(=O)c1cc(O)c(O)c(O)c1</smiles>

$1: \mathrm{R}=\mathrm{H}$

2: $\mathrm{R}=\mathrm{CH}_{3}$

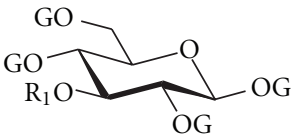

3: $\mathrm{R}_{1}=\mathrm{H}$

4: $\mathrm{R}_{1}=\mathrm{G}$<smiles>CC(=O)c1cc(O)c(O)c(O)c1</smiles>

$\mathrm{G}=$ galloyl

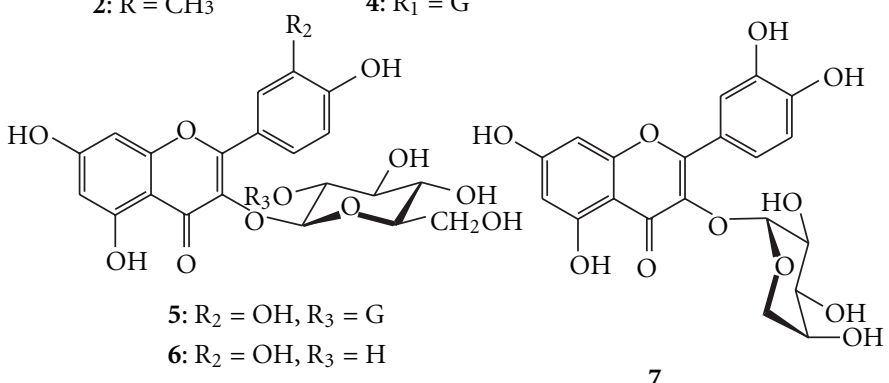

8: $\mathrm{R}_{2}=\mathrm{H}, \mathrm{R}_{3}=\mathrm{H}$

FIgURE 2: HPLC chromatograms and the major phytochemicals of EA5, EA6, and EA7 from the leaves of A. oliverianum. (1) Gallic acid, (2) gallic acid methyl ester, (3) 1,2,4,6-O-tetra-galloyl- $\beta$-D-glucopyranoside, (4) 1,2,3,4,6-O-penta-galloyl- $\beta$-D-glucopyranoside, (5) quercetin 3-O- $\beta$-D-(2" -galloyl)-glucopyranoside, (6) quercetin 3-O- $\beta$-D-glucopyranoside, (7) quercetin 3-O- $\alpha$-L-arabinopyranoside, and (8) kaempferol 3-O- $\beta$-D-glucopyranoside.

TABle 3: Mobile phase, yields, and DPPH radical scavenging activity of EtOAc soluble fraction from the A. oliverianum leaves.

\begin{tabular}{lcccc}
\hline Subfractions & Mobile phase $^{\mathrm{a}}(\mathrm{v} / \mathrm{v})$ & Yields $(\mathrm{wt} \%)$ & DPPH radical inhibition $(100 \mu \mathrm{g} / \mathrm{mL})$ & DPPH radical inhibition $(10 \mu \mathrm{g} / \mathrm{mL})$ \\
\hline EA1 & $5 / 95(\mathrm{E} / \mathrm{H})$ & 0.9 & 8.2 & $<10$ \\
EA2 & $10 / 90(\mathrm{E} / \mathrm{H})$ & 0.2 & 27.7 & $<10$ \\
EA3 & $20 / 80(\mathrm{E} / \mathrm{H})$ & 0.5 & 27.6 & $<10$ \\
EA4 & $30 / 70(\mathrm{E} / \mathrm{H})$ & 1.0 & 90.7 & 50.8 \\
EA5 & $50 / 50(\mathrm{E} / \mathrm{H})$ & 4.7 & 90.3 & 90.7 \\
EA6 & $70 / 30(\mathrm{E} / \mathrm{H})$ & 23.9 & 90.3 & 89.7 \\
EA7 & $100 / 0(\mathrm{E} / \mathrm{H})$ & 31.6 & 90.0 & 89.7 \\
EA8 & $10 / 90(\mathrm{M} / \mathrm{E})$ & 29.3 & 90.0 & 73.9 \\
EA9 & $30 / 70(\mathrm{M} / \mathrm{E})$ & 7.6 & 89.7 & 80.4
\end{tabular}

${ }^{\mathrm{a} E:}$ Ethyl acetate; H: $n$-Hexane; M: Methanol.

TABLe 4: Antioxidant activities and contents of major phytochemicals from the A. oliverianum leaves.

\begin{tabular}{|c|c|c|c|}
\hline \multirow{2}{*}{ Phytochemicals } & \multirow{2}{*}{ Contents (mg/g of methanolic extract) } & \multicolumn{2}{|c|}{ Free radical scavenging activity $\left(\mathrm{IC}_{50}, \mu \mathrm{M}\right)$} \\
\hline & & DPPH radical & Superoxide radical \\
\hline 1 & $2.75 \pm 0.08^{\mathrm{C}}$ & $8.2 \pm 0.2^{\mathrm{CD}}$ & $16.2 \pm 1.3^{\mathrm{B}}$ \\
\hline 2 & $0.41 \pm 0.01^{\mathrm{E}}$ & $8.6 \pm 0.2^{\mathrm{C}}$ & $>50$ \\
\hline 3 & $3.42 \pm 0.08^{\mathrm{A}}$ & $3.0 \pm 0.1^{\mathrm{F}}$ & $10.3 \pm 1.0^{\mathrm{C}}$ \\
\hline 4 & $3.37 \pm 0.05^{\mathrm{A}}$ & $2.8 \pm 0.1^{\mathrm{F}}$ & $6.5 \pm 0.4^{\mathrm{D}}$ \\
\hline 5 & $3.55 \pm 0.04^{\mathrm{A}}$ & $5.9 \pm 0.1^{\mathrm{E}}$ & $8.6 \pm 0.2^{\mathrm{CD}}$ \\
\hline 6 & $2.64 \pm 0.05^{\mathrm{C}}$ & $11.6 \pm 0.4^{\mathrm{B}}$ & $17.4 \pm 0.3^{\mathrm{B}}$ \\
\hline 7 & $2.95 \pm 0.05^{\mathrm{B}}$ & $19.6 \pm 0.7^{\mathrm{A}}$ & $18.1 \pm 0.7^{\mathrm{B}}$ \\
\hline 8 & $0.73 \pm 0.06^{\mathrm{D}}$ & $>50$ & $>50$ \\
\hline$(+)$-Catechin & - & $7.7 \pm 0.1^{\mathrm{D}}$ & $47.1 \pm 0.4^{\mathrm{A}}$ \\
\hline
\end{tabular}

Results are mean $\pm \mathrm{SD}(n=3)$. Different capital letters in superscript indicate significant differences among groups $(P<0.05)$. 
collected weight (wt\%) and DPPH radical scavenging activity for these 9 subfractions. Of these, the EA5, EA6, and EA7 exhibited the strongest inhibitory activity against DPPH radical. In addition, by HPLC separation, 8 specific antioxidants, including gallic acid (1), gallic acid methyl ester (2), 1,2,4,6-O-tetra-galloyl- $\beta$-D-glucopyranoside (3), 1,2,3,4,6$O$-penta-galloyl- $\beta$-D-glucopyranoside (4), quercetin $3-O-\beta$ D-(2" -galloyl)-glucopyranoside (5), quercetin 3-O- $\beta$-D-glucopyranoside (6), quercetin 3-O- $\alpha$-L-arabinopyranoside (7), and kaempferol 3-O- $\beta$-D-glucopyranoside $(8)$ were further isolated from the EA 5, EA6, and EA7 (Figure 2), and their contents were determined to be $2.75 \pm 0.08,0.41 \pm 0.01$, $3.42 \pm 0.08,3.37 \pm 0.05,3.55 \pm 0.04,2.64 \pm 0.05,2.95 \pm 0.05$, and $0.73 \pm 0.06 \mathrm{mg}$ per gram of crude extract, respectively (Table 4). As shown in Table 4, 1,2,4,6-O-tetra-galloyl- $\beta$-D-glucopyranoside (3), 1,2,3,4,6-O-penta-galloyl- $\beta$ $\mathrm{D}$-glucopyranoside (4) exhibited the strongest DPPH radical scavenging activity, and their $\mathrm{IC}_{50}$ values were 3.0 and $2.8 \mu \mathrm{M}$, respectively. In addition, the decreasing superoxide radical scavenging activity order of 8 phytochemicals in NBT assay can be ranked as $4>5>3>1>6>7 \gg 2 \& 8$. In other words, except for compounds $\mathbf{2}$ and $\mathbf{8}$, all the other compounds exhibited an excellent superoxide radical scavenging activity. Furthermore, the results indicated that compounds 3 and 4 (both belonging to hydrolysable tannins group) were the major bioactive phytochemicals in the extracts of A. oliverianum leaves. The DPPH radical and superoxide radical scavenging activities of these two phytochemicals were totally higher than those of $(+)$-catechin. This result also implied that the galloyl moiety played an important role for enhancing antioxidant activities. On the other hand, comparison of the antioxidant activity of flavonoid glycosides (compounds 5-8), we found that quercetin 3-O- $\beta$-Dglucopyranoside (6) was more powerful antioxidant than kaempferol 3-O- $\beta$-D-glucopyranoside (8). Accordingly, it revealed that $3^{\prime}, 4^{\prime}$-dihydroxyl group on the B-ring could enhance the antioxidant activity of flavonoids. Additionally, the antioxidant activity of quercetin $3-O-\beta-\mathrm{D}-\left(2^{\prime \prime}\right.$-galloyl $)$-glucopyranoside (5) was better than quercetin 3-O- $\beta$-D-glucopyranoside (6). This result also indicated that gallate acylation on the glycoside moiety could be related to enhancing their antioxidant activity.

\section{Conclusions}

The leaf extracts of different indigenous species in Taiwan were assayed to explore their antioxidant activities. These results indicate that a number of extracts present significant antioxidant activities. Among 18 tree species, the A. oliverianum leaves extracts exhibited the strongest antioxidant activity, especially on the EtOAc soluble fraction, and 8 specific and excellent antioxidants were detected and identified. These results imply that the extracts or the derived phytochemicals from A. oliverianum leaves could be used to prevent diseases caused by the overproduction of radicals and might also be suitable for the treatment of degenerative diseases.

\section{Acknowledgment}

This work was financially supported by a research grant from the Experiment Forest of National Chung Hsing University.

\section{References}

[1] B. Halliwell, "Antioxidants and human disease: a general introduction," Nutrition Reviews, vol. 55, no. 1, pp. S44-S52, 1997.

[2] B. N. Ames, L. S. Gold, and W. C. Willett, "The causes and prevention of cancer," Proceedings of the National Academy of Sciences of the United States of America, vol. 92, no. 12, pp. 5258-5265, 1995.

[3] B. L. Halvorsen, K. Holte, M. C. W. Myhrstad et al., "A systematic screening of total antioxidants in dietary plants," Journal of Nutrition, vol. 132, no. 3, pp. 461-471, 2002.

[4] B. Ou, D. Huang, M. Hampsch-Woodill, J. A. Flanagan, and E. K. Deemer, "Analysis of antioxidant activities of common vegetables employing oxygen radical absorbance capacity (ORAC) and ferric reducing antioxidant power (FRAP) assays: a comparative study," Journal of Agricultural and Food Chemistry, vol. 50, no. 11, pp. 3122-3128, 2002.

[5] V. Exarchou, N. Nenadis, M. Tsimidou, I. P. Gerothanassis, A. Troganis, and D. Boskou, "Antioxidant activities and phenolic composition of extracts from Greek oregano, Greek sage, and summer savory," Journal of Agricultural and Food Chemistry, vol. 50, no. 19, pp. 5294-5299, 2002.

[6] S. M. Kuo, "Dietary flavonoid and cancer prevention: evidence and potential mechanism," Critical Reviews in Oncogenesis, vol. 8, no. 1, pp. 47-69, 1997.

[7] Y. T. Tung, J. H. Wu, C. Y. Hsieh, P. S. Chen, and S. T. Chang, "Free radical-scavenging phytochemicals of hot water extracts of Acacia confusaleaves detected by an on-line screening method," Food Chemistry, vol. 115, no. 3, pp. 1019-1024, 2009.

[8] S. T. Ho, Y. T. Tung, K. C. Cheng, and J. H. Wu, "Screening, determination and quantification of major antioxidants from Balanophora laxiflora flowers," Food Chemistry, vol. 122, no. 3, pp. 584-588, 2010.

[9] Y. T. Tung, K. C. Cheng, S. T. Ho et al., "Comparison and characterization of the antioxidant potential of 3 wild grapesVitis thunbergii, V. flexuosa, and V. kelungeusis," Journal of Food Science, vol. 76, no. 5, pp. C701-C706, 2011.

[10] J. H. Wu, Y. T. Tung, C. F. Chyu et al., "Antioxidant activity and constituents of extracts from the root of Garcinia multiflora," Journal of Wood Science, vol. 54, no. 5, pp. 383-389, 2008.

[11] Y. Chen, M. Wang, R. T. Rosen, and C. T. Ho, "2,2-Diphenyl1-picrylhydrazyl radical-scavenging active components from Polygonum multiflorum Thunb," Journal of Agricultural and Food Chemistry, vol. 47, no. 6, pp. 2226-2228, 1999.

[12] S. E. Choi, J. H. Yoon, H. K. Choi, and M. W. Lee, "Phenolic compounds from the root of Phragmites communis," Chemistry of Natural Compounds, vol. 45, no. 6, pp. 893-895, 2009.

[13] Y. Xiang, Y. Pei, C. Qu et al., "In vitro anti-herpes simplex virus activity of 1,2,4,6-tetra-O-galloyl- $\beta$-D-glucose from Phyllanthus emblica L. (Euphorbiaceae)," Phytotherapy Research, vol. 25, no. 7, pp. 975-982, 2011.

[14] G. Beretta, R. Artali, E. Caneva, and R. Maffei Facino, "Conformation of the tridimensional structure of 1,2,3,4,6-pentagalloyl- $\beta$-D-glucopyranose (PGG) by $1 \mathrm{H}$ NMR, NOESY and theoretical study and membrane interaction in a simulated phospholipid bilayer: a first insight," Magnetic Resonance in Chemistry, vol. 49, no. 3, pp. 132-136, 2011. 
[15] M. Kuroyanagi, Y. Yamamoto, S. Fukushima, A. Ueno, T. Noro, and T. Miyase, "Chemical stusies on the constituents of Polygonum nodosum," Chemical and Pharmaceutical Bulletin, vol. 30, no. 5, pp. 1602-1608, 1982.

[16] K. Kazuma, N. Noda, and M. Suzuki, "Malonylated flavonol glycosides from the petals of Clitoria ternatea," Phytochemistry, vol. 62, no. 2, pp. 229-237, 2003.

[17] T. Stark, S. Bareuther, and T. Hofmann, "Sensory-guided decomposition of roasted cocoa nibs (Theobroma cacao) and structure determination of taste-active polyphenols," Journal of Agricultural and Food Chemistry, vol. 53, no. 13, pp. 54075418, 2005.

[18] F. Yu, J. Sheng, J. Xu, X. An, and Q. Hu, "Antioxidant activities of crude tea polyphenols, polysaccharides and proteins of selenium-enriched tea and regular green tea," European Food Research and Technology, vol. 225, no. 5-6, pp. 843-848, 2007.

[19] M. T. Chua, Y. T. Tung, and S. T. Chang, "Antioxidant activities of ethanolic extracts from the twigs of Cinnamomum osmophloeum," Bioresource Technology, vol. 99, no. 6, pp. 19181925, 2008.

[20] Y. T. Tung, J. H. Wu, and S. T. Chang, "Preliminary studies on the antioxidant activity of ethanolic extracts from the twig of Acacia confusa Merr," Quarterly Journal of Chinese Forestry, vol. 38, no. 3, pp. 367-375, 2005.

[21] Z. Huang, K. Hashida, R. Makino et al., "Evaluation of biological activities of extracts from 22 African tropical wood species," Journal of Wood Science, vol. 55, no. 3, pp. 225-229, 2009.

[22] J. H. Wu, C. Y. Huang, Y. T. Tung, and S. T. Chang, "Online RP-HPLC-DPPH screening method for detection of radicalscavenging phytochemicals from flowers of Acacia confusa," Journal of Agricultural and Food Chemistry, vol. 56, no. 2, pp. 328-332, 2008.

[23] Y. T. Tung, J. H. Wu, Y. H. Kuo, and S. T. Chang, "Antioxidant activities of natural phenolic compounds from Acacia confusa bark," Bioresource Technology, vol. 98, no. 5, pp. 1120-1123, 2007.

[24] H. Wangensteen, A. B. Samuelsen, and K. E. Malterud, "Antioxidant activity in extracts from coriander," Food Chemistry, vol. 88, no. 2, pp. 293-297, 2004.

[25] V. V. Kedage, J. C. Tilak, G. B. Dixit, T. P. A. Devasagayam, and M. Mhatre, "A study of antioxidant properties of some varieties of grapes (Vitis vinifera L.)," Critical Reviews in Food Science and Nutrition, vol. 47, no. 2, pp. 175-185, 2007.

[26] M. H. Gordon, "The mechanism of the antioxidant action in vitro," in Food Antioxidants, B. J. F. Hudson, New York, NY, USA, 1990. 


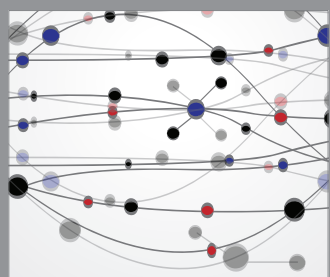

The Scientific World Journal
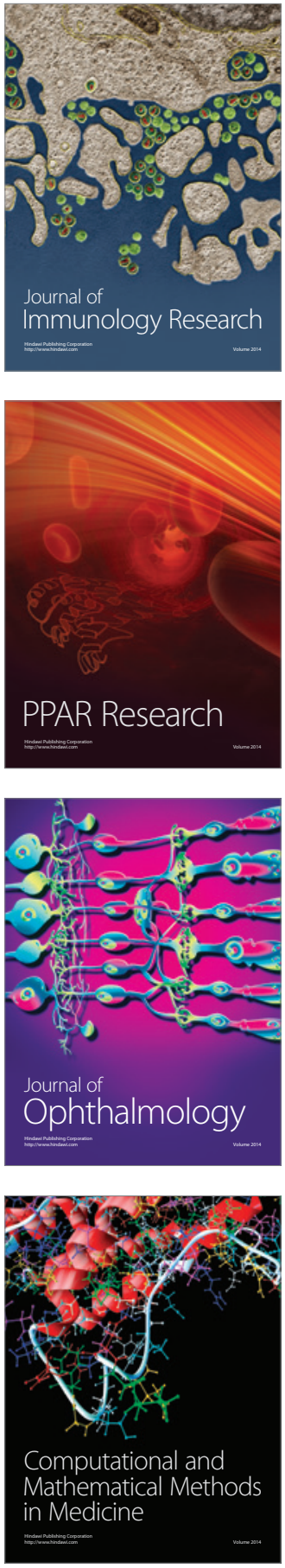

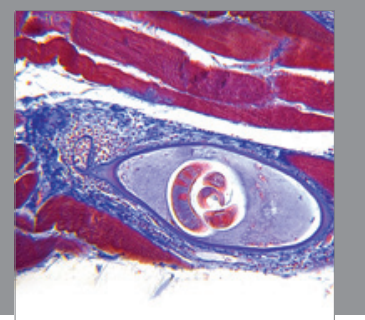

Gastroenterology

Research and Practice
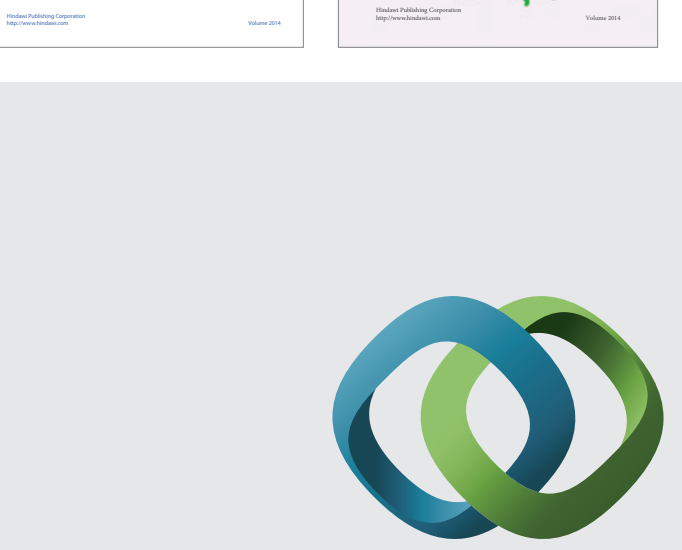

\section{Hindawi}

Submit your manuscripts at

http://www.hindawi.com
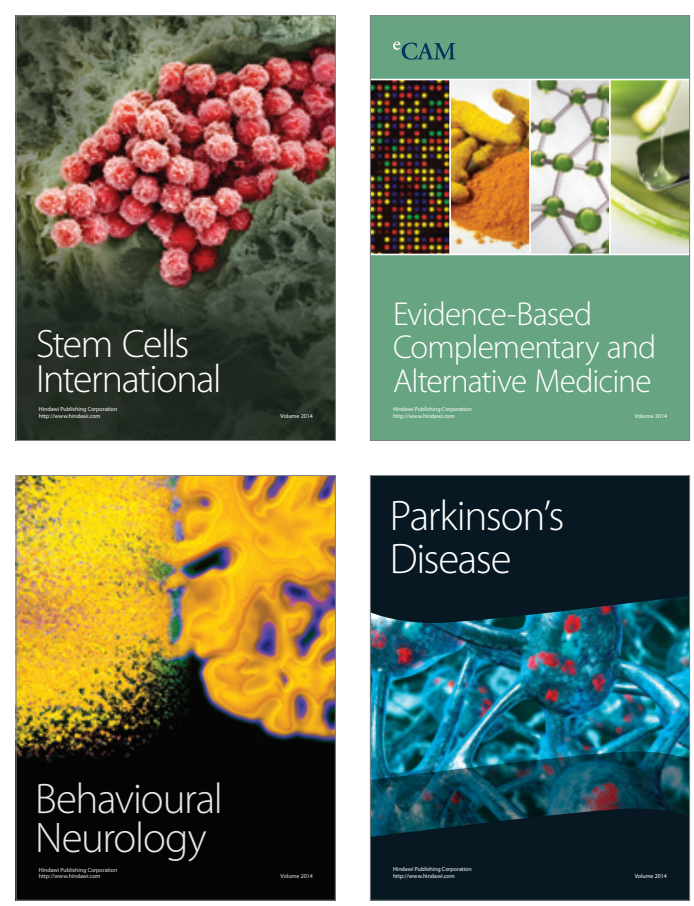

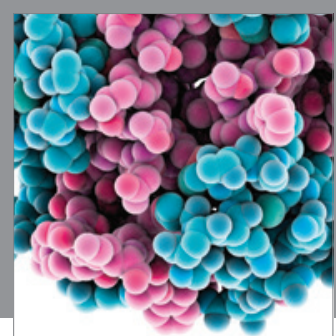

Journal of
Diabetes Research

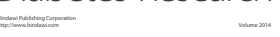

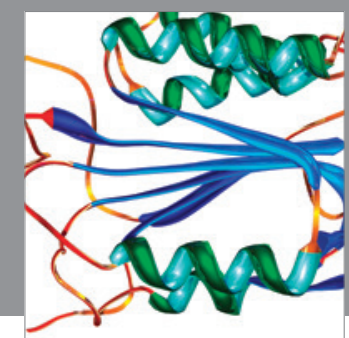

Disease Markers
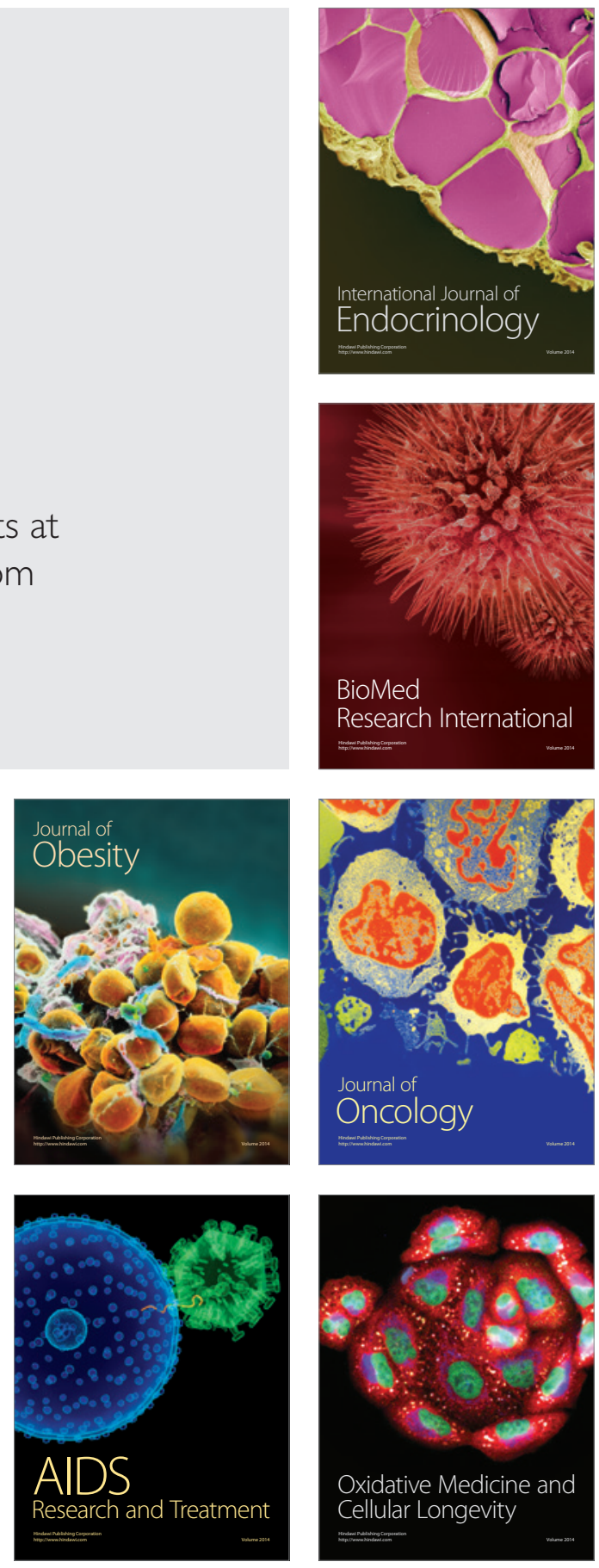